\title{
Differential expression of the $\alpha 2,3$-sialic acid residues in breast cancer is associated with metastatic potential
}

\author{
HONGXIA CUI ${ }^{1,2^{*}}$, YU LIN $^{1 *}$, LILING YUE ${ }^{3}$, XUEMEI ZHAO ${ }^{1 *}$ and JICHENG LIU ${ }^{3}$ \\ ${ }^{1}$ Department of Pharmacology, Qiqihar Medical College, Qiqihar, Heilongjiang; ${ }^{2}$ Heilongjiang University of Chinese \\ Medicine, Harbin 150040; ${ }^{3}$ Institute of Medicine, Qiqihar Medical College, Qiqihar, Heilongjiang, P.R. China
}

Received November 4, 2010; Accepted January 24, 2011

DOI: 10.3892/or.2011.1192

\begin{abstract}
Aberrant sialylation is closely associated with the malignant phenotype of cancer cells and metastatic potential. However, the precise nature of the molecules in breast cancers has not been unveiled. In this study, we investigated the expression levels of $\alpha 2,3$-sialic acid residues of 50 primary tumor cases, 50 pair-matched lymph node metastasis tumor samples and in the MDA-MB-231, T-47D and MCF-7 breast cancer cell lines with different metastatic potential. The expression of $\alpha 2,3$-sialic acid residues was analyzed by histochemistry, cytochemistry and flow cytometry with Maackia amurensis lectin (MAL). The invasion and migration abilities of cells were examined using cell adhesion and transwell in vitro assays. Pair-matched lymph node metastasis tumor samples exhibited higher levels of expression of $\alpha 2,3$-sialic acid residues compared to that of primary tumors $(\mathrm{P}=0.0432)$. Furthermore, of 38 tumors cases in $\mathrm{T} 1 / \mathrm{T} 2$ stages, $31(81.58 \%)$ had weak staining for MAL, which specifically binds to $\alpha 2,3$-sialic acid residues, whereas of 12 tumor cases in T3/T4 stages, only 1 (8.33\%) had weak reactions for MAL. The highly metastatic breast cancer cell line MDA-MB-231 exhibited the strongest binding to MAL and the highest expression levels of $\alpha 2,3$-sialic acid residues among the selected cell lines, depending on mRNA expression levels of $\alpha 2,3$-sialyltransferase gene. The adhesion, invasion and migration activities confirmed that MDA-MB-231 exhibited the greater cell adhesion to, migration toward and invasion to Matrigel. Taken together, the high expression of $\alpha 2,3$-sialic acid residues in breast cancer was associated with metastatic potential. This property may be important for developing new therapeutic approaches for breast cancer.
\end{abstract}

Correspondence to: Dr Ji-Cheng Liu, The Institute of Medicine, Qiqihar Medical Univeristy, 333 BuKui Street, JianHua District, Qiqihar, Heilongjiang 161042, P.R. China

E-mail: qyybliu@sohu.com

${ }^{*}$ Contributed equally

Key words: $\alpha 2,3$-sialic acid residues, maackia amurensis lectin, human breast cancer, invasion and metastasis

\section{Introduction}

Aberrant sialylation is most ubiquitous in malignant tumor cells. Sialic acids, as terminal monosaccharide were added to protein or lipid moieties, linked to Galb1,3(4)GlcNAc/Glc via $\alpha 2,3$ or $\alpha 2,6$ and mediated a variety of pathological process. The altered sialic acid residues are closely associated with the malignant phenotype of cancer cells and metastatic potential (1-4). The correlation between sialic acids content and tumor metastatic potential has been reported in many tumors and has received much attention recently. It has been proven that aberrant expression of terminal sialic acids, and in particular $\alpha 2,3$-sialic acids are related to tumor adhesion and invasion $(5,6)$. High levels of sialylation of cell surface glycoconjugates could significantly increase metastasis of colon carcinoma cells and human melanoma cells (7-9). Expressions of $\alpha 2,3-$ sialic acid residues of $\mathrm{N}$-cadherin were altered in metastatic melanoma cell lines (10). This possibility is further supported in the experiment where soyasaponin I significantly impaired metastatic ability of breast cancer by decreasing expression of cell surface $\alpha 2,3$-sialic acids (11). Inhibition expression of $\alpha 2,3$-sialic acid residues may decrease the migratory ability of highly metastatic B16F10 melanoma cells (12).

To the best of our knowledge, the precise nature of the molecules has not been fully unveiled nor documented to be of clinical relevance, although the elevated expression of sialylation residues in breast cancer has been reported $(13,14)$. In this study, we investigated the expression of $\alpha 2,3$-sialic acid residues of 50 primary tumor cases, 50 pair-matched lymph node metastasis tumor samples and in three breast cancer cell lines with different metastatic potential (MDAMB-231, T-47D, and MCF-7) using a specific lectin, and the association of invasion and metastasis was analyzed.

\section{Materials and methods}

Tumor samples. Tissue samples of 100 patients who underwent surgery were obtained from tissue array (Shanxi Chaoying Biotechnology Co., Ltd., China). There were 50 primary tumors and 50 pair-matched lymph node metastasis tumors. Age of the patients ranged from 28 to 80 years with a mean of 50.4 years. Depth of invasion, 10 tumors were staged T1, 28 as T2, 8 as T3, and 4 as T4, based on International Union Against Cancer (UICC) TNM staging system (15). 
MAL histochemistry. Paraffin-embedded specimens were dewaxed and repaired for $10 \mathrm{~min}$ at $121^{\circ} \mathrm{C}$. Endogenous peroxidase activity was quenched with $3 \%$ hydrogen peroxide/ methanol at room temperature. The sections were incubated for $20 \mathrm{~min}$ in goat serum to block non-specific binding and then incubated with $20 \mu \mathrm{g} / \mathrm{ml}$ biotinylated MAL (Vector Laboratories, Inc., USA) at $4^{\circ} \mathrm{C}$ overnight. The bound biotinylated MAL was detected by biotin-streptavidin-peroxidase (Beijing Zhongshan Biotechnology Co., Ltd.). 3,3'-diaminobenzidine (DAB) was used as chromogen and haematoxylin was used for nucleus counterstain. One thousand cells of each section were randomly selected and counted blindly. The positive percentage of counted cells was semi-quantitated according to a 2-tier scoring system: weakly positive, 1-40\%; and strongly positive, $41-100 \%$ (16). The slides were photographed under a Nikon Eclipse TE2000-S Inverted microscope (magnification, $\mathrm{x} 200)$.

Cell lines and cell culture. Human breast cancer cells lines, MCF-7, T-47D and MDA-MB-231, were purchased from Shanghai Cell Bank, Chinese Academy of Sciences (Shanghai, China). MCF-7 and T-47D were cultured in DMEM medium with high glucose. MDA-MB-231 cells were cultured in L15 medium (Gibco ${ }^{\mathrm{TM}}$ Invitrogen Corp., USA). Medium was supplemented with $10 \%$ heat-inactivated fetal bovine serum (FBS), penicillin-streptomycin (100 IU/ml-100 $\mu \mathrm{g} / \mathrm{ml})$. Cells were fed every 3 days at $37^{\circ} \mathrm{C}$ in a humid atmosphere $5 \%$ $\mathrm{CO}_{2}$ ) and harvested by $0.25 \%$ trypsin.

Cytochemical staining. Cells were grown on glass coverslips, after achieving confluence, they were treated with or without neuraminidase (Sigma) for $1 \mathrm{~h}$ at $37^{\circ} \mathrm{C}$, coverslips were washed three times with PBS and fixed with $95 \%$ alcohol at $4^{\circ} \mathrm{C}$ for $20 \mathrm{~min}$. The cells labeling with biotinylated MAL (10 $\mu \mathrm{g} / \mathrm{ml}$ ) were performed as detailed above. One hundred cells were randomly selected and photographed from representative fields of each coverslip, cells were evaluated as previously described.

Flow cytometric analysis. To detect sialylation structures of cell surface glycoproteins and glycolipids, we used FITCconjugated MAL (Vector Laboratories, Inc.), which is specific for binding to $\alpha 2,3$-sialic acid residues. Cells were detached with $0.25 \%$ trypsin-EDTA solution, then washed three times with PBS, adjusted cells density $3 \times 10^{6} / \mathrm{ml}$, stained with $10 \mu \mathrm{g} / \mathrm{ml}$ FITC-MAL in PBS (contain $0.5 \%$ BSA and $0.05 \%$ sodium azide) at $4^{\circ} \mathrm{C}$ for $1 \mathrm{~h}$, then washed three times with PBS. The fluorescence intensity of the stained cells was measured with a FACScan flow cytometer and analyzed with CellQuest (BD, Bioscience, USA).

$R T$-PCR . Sialic acids, as terminal sugars were added by sialyltransferase. Reverse transcriptase polymerase chain reaction for studying mRNA level expression of $\alpha 2,3$-sialyltransferase $(\alpha 2,3-\mathrm{ST})$ gene in breast cancer cell lines. Cellular total RNA was extracted using TRIzol (Invitrogen). Subsequently, RNAs were reverse-transcribed using RNA Miniprep Kit (Takara Biotechnology Co., Ltd.). PCR amplification reaction was conducted with the following primers: $\alpha 2,3-\mathrm{ST}$ forward, 5'-CGC AAA CTT TTC AGA GGG AG-3'; reverse, 5'-AAG
AGA GAA TCG CGC TCG TA-3'. The $\beta$-actin forward, 5'-GTG GAC ATC CGC AAA GAC-3'; reverse, 5'-GAA AGG GTG TAA CGC AAC T-3'. PCR products were run on $1.0 \%$ agarose gel and the intensity of each band was quantified using Scion Image software (Scion, Frederick, MD). Results for each detected band intensity were normalized to $\beta$-actin band intensity values.

Cell-Matrigel adhesion assay. The 96-well plates were precoated with $25 \mu \mathrm{g}$ /well of Matrigel basement membrane extract (BD Bioscience, USA). The $1 \times 10^{5}$ cells (control or neuraminidase-treated) were labeled by Chloromethyl-benzamidodialkylcarbo-cyanine (CM-Dil) $3 \mu \mathrm{g} / \mathrm{ml}$ for $2 \mathrm{~h}$ at $37^{\circ} \mathrm{C}$. They were seeded into the precoated wells and incubated for $30 \mathrm{~min}$ at $37^{\circ} \mathrm{C}$ in $5 \% \mathrm{CO}_{2}$ incubator. The cells were washed twice with PBS gently to remove unattached cells, the numbers of cell attached to the Matrigel were counted in five randomly selected microscopic fields per well and photographed under a fluorescence microscope. Independent experiments were performed at least three times.

In vitro migration and invasion assay. Tumor cell migration and invasion were measured using 24-well transwell chamber (Costar Corp., USA), which consists of upper and lower chambers that were separated by Millipore membranes with $8-\mu \mathrm{m}$ pore sizes. Cells able to move from the top surface (or procoated with Matrigel) to the under surface of the membrane were considered migration (or invasion). In brief, MCF-7, T-47D, and MDA-MB-231 cells $\left(2 \times 10^{5}\right.$ or $2.5 \times 10^{4}$ for invasion) were added to the upper chamber in serumfree medium, the lower compartment was filled with media supplemented with $10 \% \mathrm{FBS}$. After incubation at $37^{\circ} \mathrm{C}$ for $24 \mathrm{~h}$, the non-migrating cells on the upper surface of the filter were removed with cotton swabs, and the migrating cells on the lower surface were fixed with methanol for $30 \mathrm{~min}$. After drying, the fixed cells were stained with $0.1 \%$ crystal violet for $30 \mathrm{~min}$, then washed three times with PBS, photographed under a fluorescence microscope and incorporated dye was dissolved in $10 \%$ acetic acid. The optical densities of each well were measured by ELISA reader at $570 \mathrm{~nm}$. Experiments were performed in triplicate.

Statistical analysis. The data were expressed as the mean \pm SD and analyzed by SPSS 13.0 statistical software to evaluate the statistical difference. P-value $<0.05$ was considered statistically significant. The relationship between the expression of $\alpha 2,3$-sialic acid residues and patient's clinical characteristics was analyzed by the $\chi^{2}$-test. One-way ANOVA analysis was used to evaluate the results of cell adhesion assays and transwell chamber assay.

\section{Results}

Expression of $\alpha 2,3$-sialic acid residues in breast cancer samples correlated with clinicopathological characteristics. The expressions of $\alpha 2,3$-sialic acid residues were observed by using MAL staining. The result showed positive MAL binding reaction in breast cancer regions, whereas there was negative staining in the stromal parts (Fig. 1A). Pair-matched lymph node metastasis tumors exhibited more frequent and 

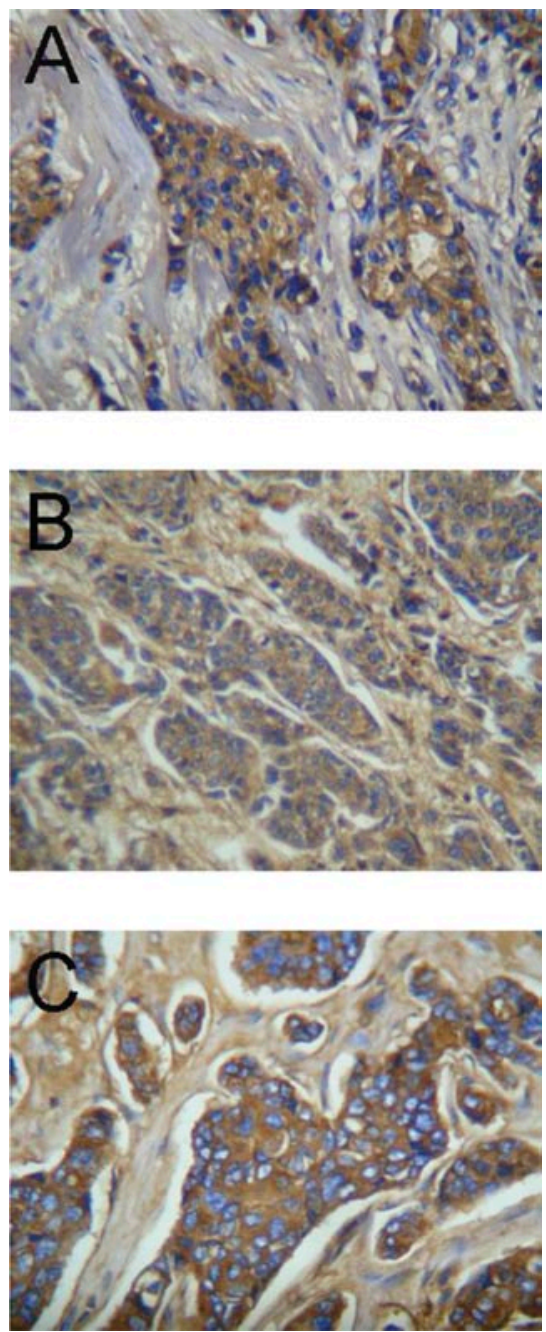

Figure 1. Histochemical staining with MAL in breast cancer tissues. (A) MAL staining is the positive reaction in breast cancer regions, whereas negative MAL staining was observed in the stromal part. (B and C) MAL staining in primary cancer (B) and pair-matched lymph node metastasis $(C)$, the latter exhibited more intense positive reaction (magnification, $\mathrm{x} 200$ ).

stonger expression of $\alpha 2,3$-sialic acid residues than those in primary tumors (Fig. 1B). Furthermore, of 38 tumor cases in T1/T2 stages, $31(81.58 \%)$ had weak staining for MAL, whereas of 12 tumors cases in T3/T4 stages, only $1(8.33 \%)$ had weak reactions for MAL. High expression of $\alpha 2,3$-sialic acid residues was closely associated with tumor invasive depth $(\mathrm{P}<0.05)$ and lymphatic metastasis. However, the relationship between intensity of $\alpha 2,3$-sialic acid residues and age was not observed.

Different expression of $\alpha 2,3$-sialic acid residues in breast cancer cell lines. The expression of $\alpha 2,3$-sialic acid residues was examined in three human breast cancer cell lines with different metastatic potential, MDA-MB-231, T-47D, and MCF-7. As shown in Fig. 2, MAL staining was on cell membrane or in cell cytoplasm. The highly metastatic breast cancer cell line MDA-MB-231 shows the most intensive staining compared with T-47D and MCF-7 (Fig. 2A-C). All the binding reactions were inhibited by neuraminidase treatment, indicating that the staining of cells was due to
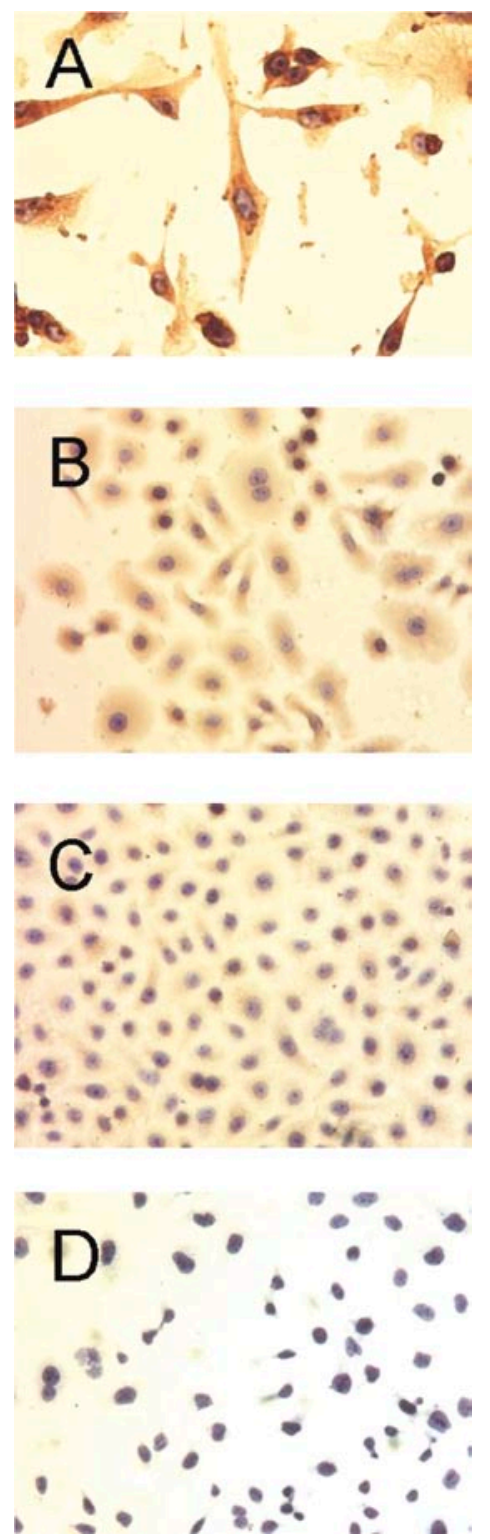

Figure 2. Cytochemical analyses of MAL staining in breast cancer cells MDA-MB-231 (A) shows the most intense staining compared with T-47D (B) and MCF-7 (C). (D) MAL reaction was inhibited by pre-treatment with neuraminidase (magnification, $\times 200$ ).

the interaction between $\alpha 2,3$-sialic acid residues and MAL (Fig. 2D).

Furthermore, flow cytometric analysis was performed to study $\alpha 2,3$-sialic acid contents on cell surface by using FITC-MAL. A typical image is shown in Fig. 3. Results from three independent experiments demonstrated that the mean fluorescence intensities of MAL-labeling cells of MDA-MB231, T-47D, and MCF-7 were 1091.38 $\pm 10.78,733.80 \pm 9.47$ and $434.58 \pm 10.19$, respectively. Significant differences were seen across cell lines (MDA-MB-231 to T-47D, P<0.01; MDA-MB231 to $\mathrm{MCF}-7, \mathrm{P}<0.01)$. Those results suggest that high level of $\alpha 2,3$-sialic acid residues was expressed in the highly metastatic breast cell lines.

In breast cancer, the $\alpha 2,3$-sialyltransferase $(\alpha 2,3-\mathrm{ST})$, is mainly responsible for catalyzing sialic acids to form sialylated residues. We analyzed the mRNA levels of $\alpha 2,3-\mathrm{ST}$ by 
A
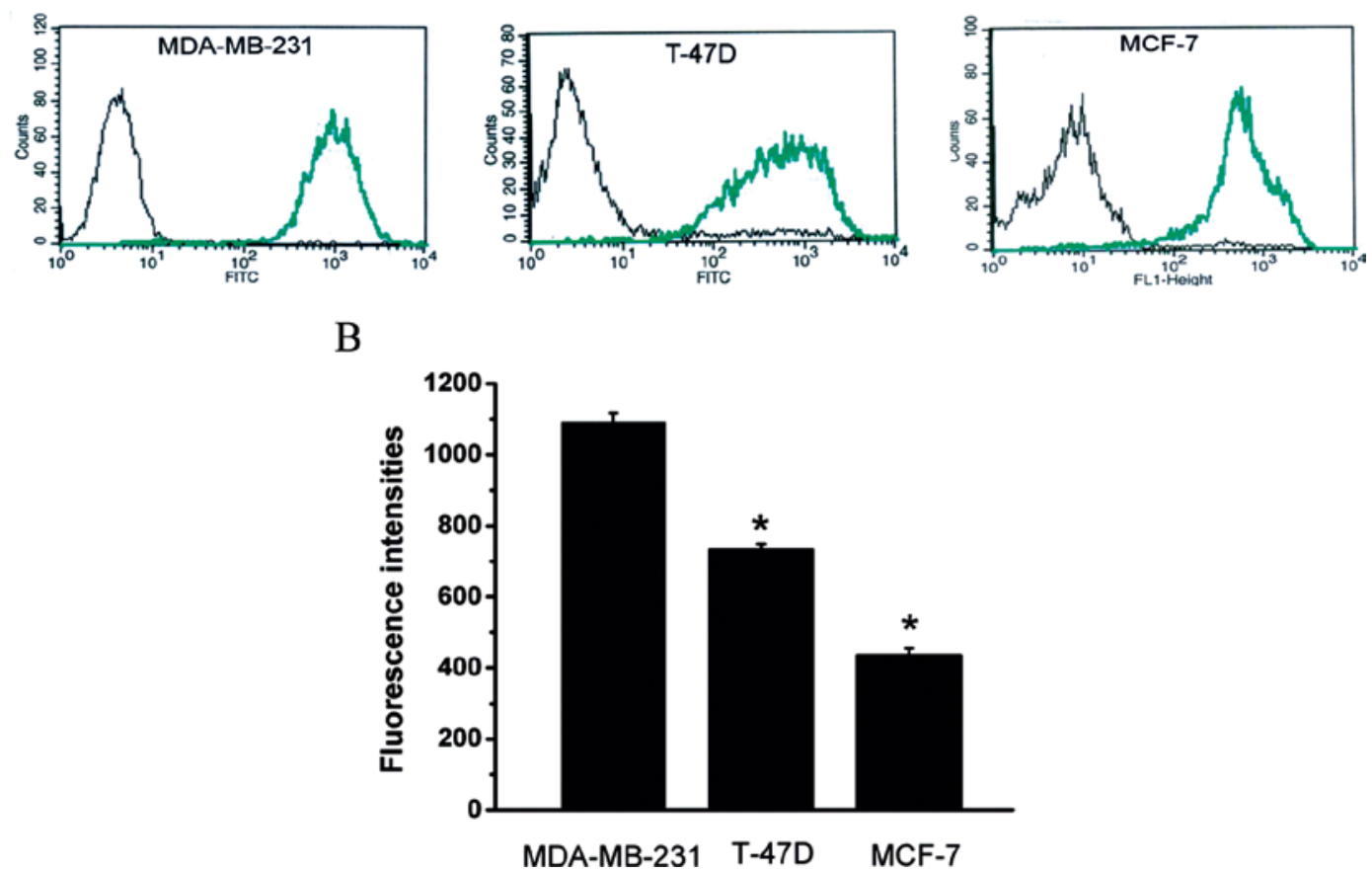

Figure 3. Flow cytometric analysis $\alpha 2,3$-sialic acid residues with FITC-MAL. Cells were incubated with FITC-MAL at $4{ }^{\circ} \mathrm{C}$ for $1 \mathrm{~h}$. The fluorescence intensities of FITC-MAL labeled cells were determined. (A) the expression of $\alpha 2,3$-sialic acid residues on the surface of MDA-MB-231 was markedly increased compared with that in T-47D and MCF-7 (green line). (B) Values of fluorescence intensity are shown as the mean \pm SD.

A

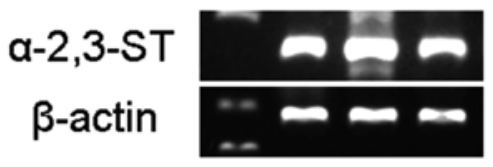

B

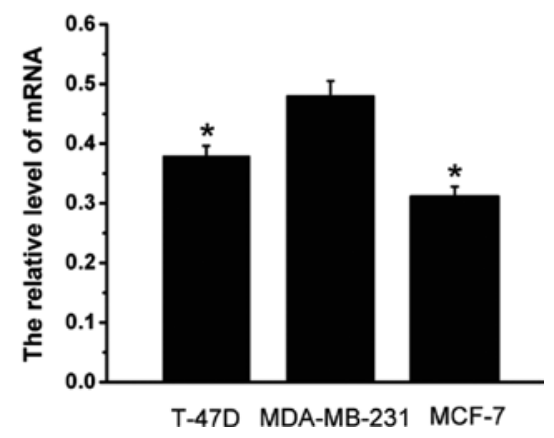

Figure 4. The mRNA expression of $\alpha 2,3$-ST gene was determined by semiquantitative RT-PCR. For one experiment, three assays were carried out, one set of gels is shown (A). The density of the band (normalized to $\beta$-actin) is shown as the mean \pm SD (B). Significant difference in the mRNA expressions of $\alpha 2,3-\mathrm{ST}$ gene were analyzed using the ANOVA $(\mathrm{n}=3)$.

semi-quantitative RT-PCR in breast cancer cell lines. The relative mRNA level of MDA-MB-231, T-47D, and MCF-7 was $0.48 \pm 0.027,0.3791 \pm 0.017,0.311 \pm 0.018$, respectively (Fig. 4). Significant differences were seen across cell lines (MDAMB-231 to T-47D, P<0.01; MDA-MB-231 to MCF-7, P<0.01).
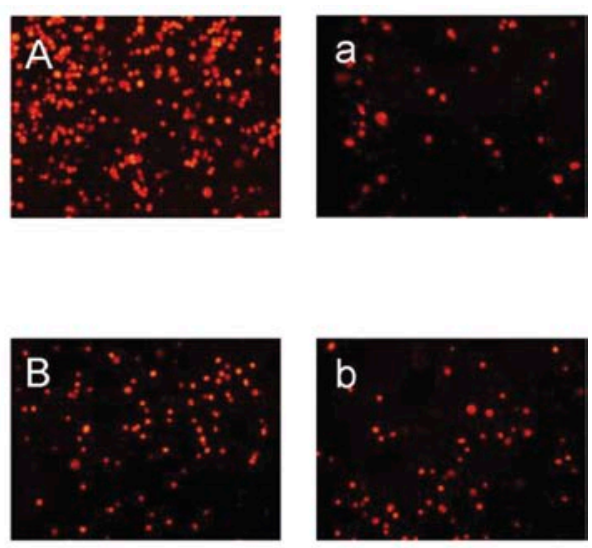

$\mathrm{C}$

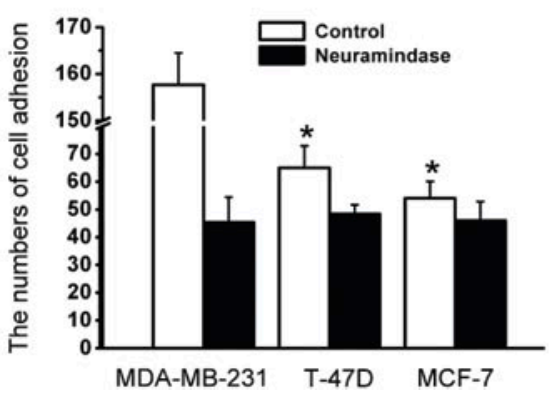

Figure 5. Cell adhesion assay. Cells were stained with Dil at $37^{\circ} \mathrm{C}$ for $2 \mathrm{~h}$ before adding to the 96-well culture plate pre-coated with Matrigel. The adhesive cells were counted and photographed in five random fields. MDAMB-231 (A) had increased adhesion ability compared with T-47D (B). After neuraminidase treatment, a significant adhesion reduction was observed from MDA-MB-231 cells (a). However, the number of adhered T-47D cells did not show a significant change (b). (C) The cell adhesion is shown as the mean $\pm \mathrm{SD}$. 

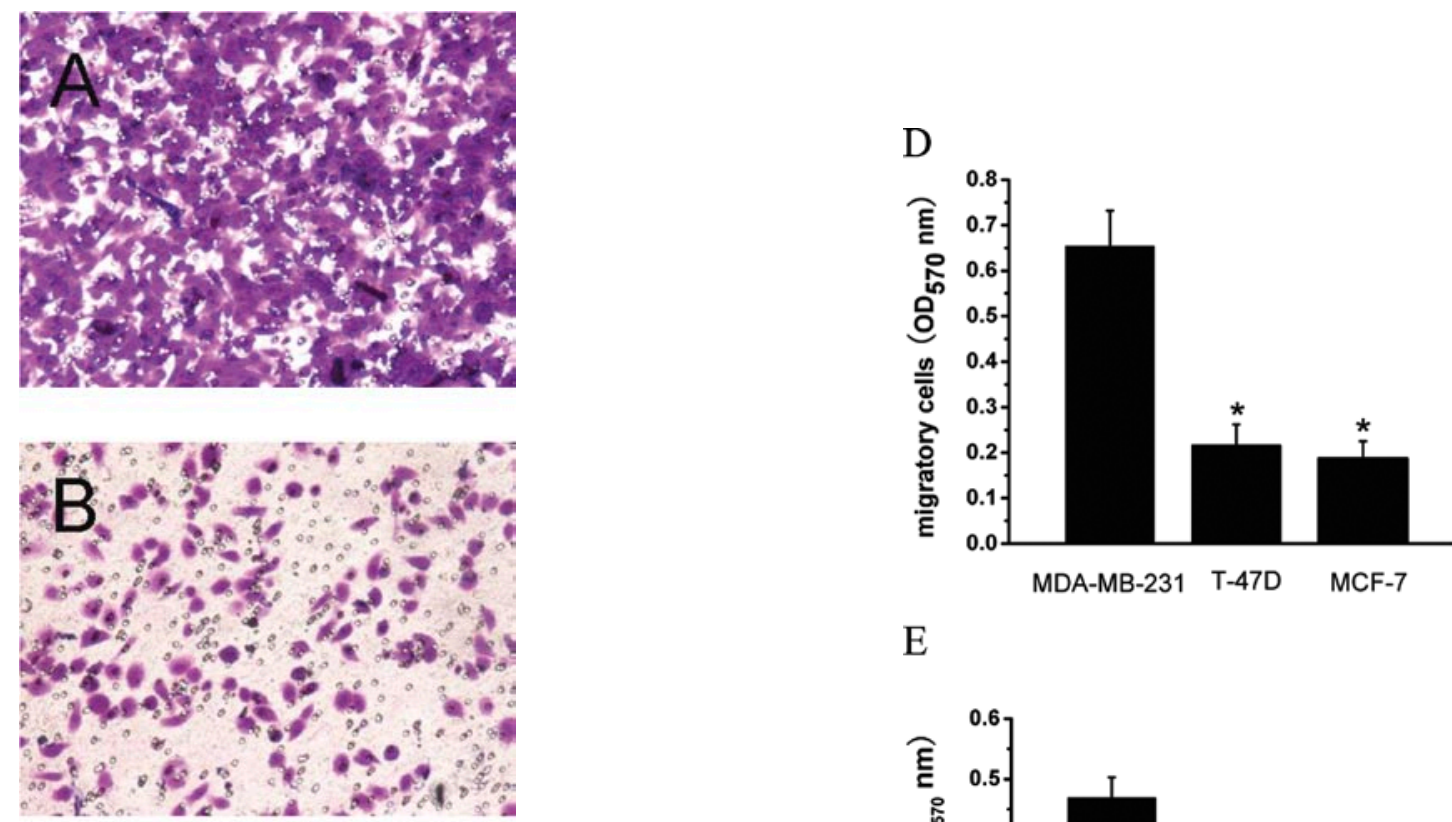

$\mathrm{E}$
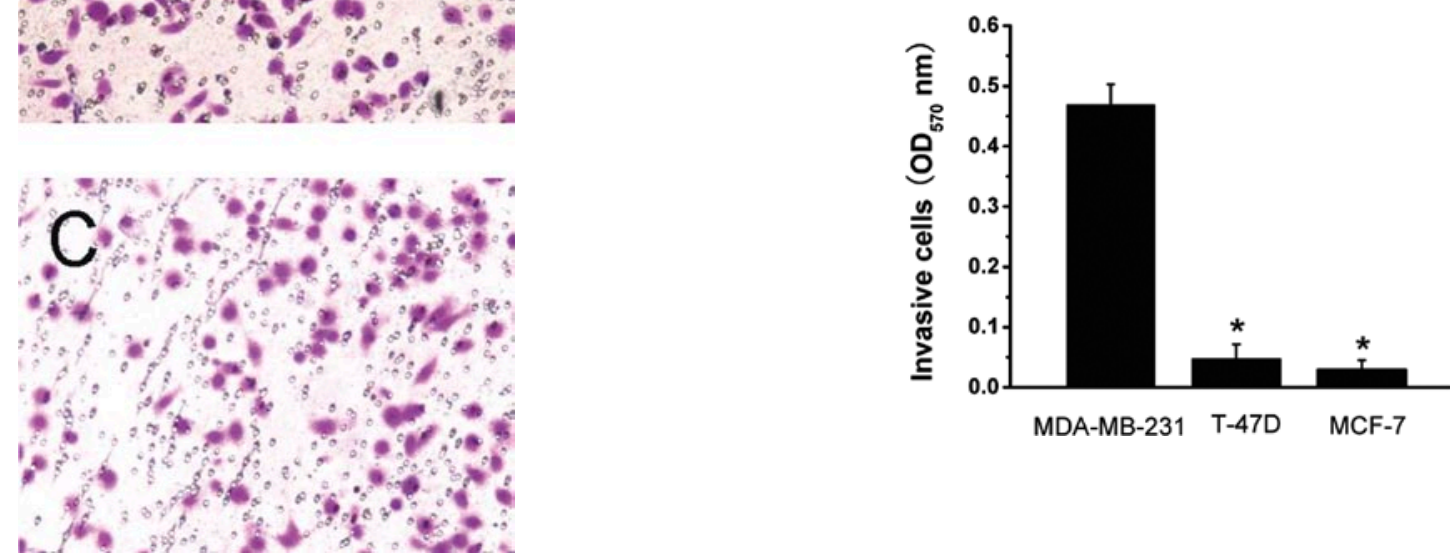

Figure 6. Cell migration and invasion were examined using a transwell chamber. The images show the crystal violet-stained breast cancer cells migrating through transwell chamber, MDA-MB-231 (A) displayed increased migratory potential compared with T-47D (B) and MCF-7 (C). (D and E) The optical densities of migration and invasion were read at $570 \mathrm{~nm}$ and are shown as the mean \pm SD. Statistical analysis was done using the ANOVA.

Cell adhesion to ECM relation to $\alpha 2,3$-sialic acid residues. The ability of adhesion to ECM was examined in different cell lines. As shown in Fig. 5, obvious differences in the cell number adhered to Matrigel were observed among cell lines. The mean number of adhesive cells of MDA-MB-231, T-47D, and MCF-7 was $157.66 \pm 6.79,65 \pm 7.87,54 \pm 6.16$, respectively. Significant differences were seen among cell lines (MDA-MB-231 to T-47D, P<0.001; MDA-MB-231 to MCF-7, P<0.001; T-47D to MCF-7, P $>0.05$ ).

After treatment with neuraminidase, the number of adherent MCF-7 and T-47D cells did not show a significant change. However, a significant adhesion reduction was observed in MDA-MB-231 cells (73.55 $\pm 9.13 \%$ inhibition, $\mathrm{P}<0.001)$.

High levels of a2,3-sialic acid residue association with promotion of cell invasion and migration. The abilities of cancer cell migration and invasion play important roles in evaluating tumor metastasis. The invasion and migration of breast cancer cell lines were measured using the transwell chamber. As shown in Fig. 6, the optical density of migration and invasion of MDA-MB-231 was $0.654 \pm 0.078,0.469 \pm 0.034$, while T-47D and MCF-7 were $0.216 \pm 0.046,0.047 \pm 0.024$ and $0.187 \pm 0.0380 .029 \pm 0.016$, respectively. Significant differences were seen in the different metastatic potential breast cell lines (MDA-MB-231 to T47D, P<0.01; MDA-MB-231 to MCF-7, $\mathrm{P}<0.01$; T-47D to MCF-7, $\mathrm{P}>0.05$ ).

\section{Discussion}

Aberrant sialylation is closely associated with the malignant phenotype of cancer cells and metastatic potential. The content of sialic acid have been elevated on some malignant tumor cells, a positive correlation between cell metastatic potential and total sialic acid content has been reported in many types of tumors. Most of these studies suggested that high level of sialylation may contribute to invasion and metastasis (17-19). The tumor dissemination is a multistep process involving aberrant biological behavior of tumor cells, such as adhesion, migration and invasion. So far, few studies on the relationship between the expression of $\alpha 2,3$-sialic acid residues in breast cancer and invasion and metastasis have been reported. Hence, we examined the expression of $\alpha 2,3-$ sialic acid residues in breast cancer using MAL staining and the significance of metastatic potential were analyzed. The results suggest that high levels of $\alpha 2,3$-sialic acid residues was closely associated with lymph node metastasis and invasive depth in breast cancer patients. Then we measured the 
expression of $\alpha 2,3$-sialic acid residues in three human breast carcer cell lines with different metastatic potential and the abilities of invasion and migration were analyzed. A positive correlation between the levels of $\alpha 2,3$-sialic acid and ability of invasion and migration was observed (Figs. 2-6).

Many studies suggested that an increased cell surface sialic acid content in cancer cells is caused by up-regulating of sialyltransferase (20-24) and depended on the mRNA levels of sialyltransferase gene (25). In breast cancer, the sialyltransferase $(\alpha 2,3-\mathrm{ST})$, is mainly responsible for catalyzing sialic acid to form $\alpha 2,3$-sialic acid residues (26). In this study, we analyzed the mRNA level of $\alpha 2,3-S T$ gene in breast cancer cell lines. The results indicated that the mRNA level of $\alpha 2,3-\mathrm{ST}$ is higher in MDA-MB-231 than that in T-47D and MCF-7. Similarly, the $\alpha 2,3$-sialic acid residues on cell surface, the products of $\alpha 2,3-\mathrm{ST}$ is highest in MDA-MB-231 by flow cytometric analysis among the selected cell lines. The highly metastatic breast cancer cell line MDA-MB-231 had higher expression of $\alpha 2,3$-sialic acid residues compared to T-47D and MCF-7 depending on the mRNA levels of $\alpha 2,3-$ ST genes. The MAL (lectin from Maackia amurensis) specifically binding the sialyl $\alpha 2,3 \mathrm{Gal} \beta 1,4 \mathrm{GlcNAc} / \mathrm{Glc}$ trisaccharide sequence (27). Furthermore, it can bind to certain sialylation residues that carry out various functions such as cell adhesion, invasion and migration. MAL, however, did not react with neuraminidase treatment. Neuraminidase cleaves terminal sialic acid residues on cell surface and changes glycan chain structures. In our study, positive MAL staining was detected in breast cancer tissue, while staining was negative in the stromal part (Fig. 1A). MAL staining was on cell membrane or in cell cytoplasm (Fig. 2A-C). All the binding reactions were inhibited by neuraminidase treatment (Fig. 2D). These proved that the staining of cells was due to the interaction between $\alpha 2,3$-sialic acid residues and MAL.

Cell migration is an essential process in metastasis. The extracellular matrix (ECM) serves as the molecular scaffold for cell adhesion and migration. In the first phase of migration, adhesion of cells to the ECM is critical. Matrigel is reconstituted basement membrane has been proved useful in the study of the molecular mechanisms of basement membrane invasion. An increasing amount of evidence proved that cell-surface carbohydrates promote the emergence of migration (28). However, the nature of the molecular have not been fully elucidated. In the present study, MDA-MB231 with high levels of $\alpha 2,3$-sialic acid residues, greater adhesion to Matrigel and the most number of cells migrated and invasion were observed. Effects of adhesion to Matrigel was significantly reduced by neuraminidase treatment, the high level of $\alpha 2,3$-sialic acid residues in MDA-MB-231 were largely inhibited $(73.55 \pm 9.13 \%$ inhibition) relative to that of

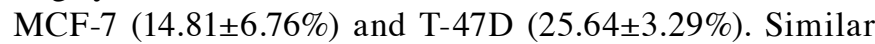
results were observed in migration and invasion assay in vitro. Thus implying that $\alpha 2,3$-sialic acid residues in human breast cancer play a pivotal role in cell adhesion, migration and invasion. We infer that the $\alpha 2,3$-sialic acid residues in human breast cancer are involved in the metastasis process.

In addition to directly modulating cell motility, $\alpha 2,3$-sialic acid residues are involved in the synthesis of sialyl Lewis $\mathrm{X}$ determinants, which are the major ligands for endothelial
E-selectin (24). The sialyl Lewis X structure on malignant cells is suggested to facilitate tumor cell dissemination by mediating the tumor-endothelial cell interactions $(29,30)$.

On the other hand, integrins represent a particularly important adhesion receptors that mediate attachment to ECM protein ligands $(31,32)$. Hypersialylation of $\beta 1$ integrins can up-regulate cell motility in colon cancer. This increased negative charged properties of sialic acids was correlated with reduced adhesiveness of tumor cells and may be suitable for conformational change of integrin and enhances its function in cell-ECM interactions (33). Similar studies have also indicated that increased sialylation could activate $\beta 1$ integrin, mediate its adhesion to ECM proteins (34) and stimulating cell migration through host ECM (35). Most of these studies and our finding supported the hypothesis that increase of sialylation of cancer cells play an important role in tumor metastasis.

In conclusion, our studies suggested that different expression of $\alpha 2,3$-sialic acid residues was associated with promoting adhesion, migration, and invasion in vitro, possibly contributing to breast cancer metastasis. This property may be meaningful to breast cancer patients in seeking novel target for therapeutic approaches.

\section{Acknowledgements}

This study was supported by National Natural Science Foundation of China (No. 30772751).

\section{References}

1. Aubert M, Panicot L, Crotte C, Gibier P, Lombardo D, Sadoulet MO and Mas E: Restoration of alpha( 1,2$)$ fucosyltransferase activity decreases adhesive and metastatic properties of human pancreatic cancer cells. Cancer Res 60: 1449-1456, 2000.

2. Zhu Y, Srivatana U, Ullah A, Gagneja H, Berenson CS and Lance P: Suppression of a sialyltransferase by antisense DNA reduces invasiveness of human colon cancer cells in vitro. Biochim Biophys Acta 1536: 148-160, 2001.

3. Gorelik E, Galili U and Raz A: On the role of cell surface carbohydrates and their binding proteins (lectins) in tumor metastasis. Cancer Metastasis Rev 20: 245-277, 2001.

4. Brooks SA, Carter TM, Royle L, et al: Altered glycosylation of proteins in cancer: what is the potential for new anti-tumour strategies. Anticancer Agents Med Chem 8: 2-21, 2008.

5. Czyzewska J, Guzińska-Ustymowicz K, Kemona A and Bandurski R: The expression of matrix metalloproteinase 9 and cathepsin B in gastric carcinoma is associated with lymph node metastasis, but not with postoperative survival. Folia Histochem Cytobiol 46: 57-64, 2008.

6. Lin S, Kemmner W, Grigull S and Schlag PM: Cell surface alpha 2,6 sialylation affects adhesion of breast carcinoma cells. Exp Cell Res 276: 101-110, 2002.

7. Inagaki Y, Tang W, Guo Q, et al: Sialoglycoconjugate expression in primary colorectal cancer and metastatic lymph node tissues. Hepatogastroenterology 54: 53-57, 2007.

8. De Albuquerque Garcia Redondo P, Nakamura CV, de Souza W and Morgado-Diaz JA: Differential expression of sialic acid and $\mathrm{N}$-acetylgalactosamine residues on the cell surface of intestinal epithelial cells according to normal or metastatic potential. J Histochem Cytochem 52: 629-640, 2004.

9. Lityńska A, Przybyło M, Pocheć E, Hoja-Łukowicz D, Ciołczyk D, Laidler P and Gil D: Comparison of the lectinbinding pattern in different human melanoma cell lines. Melanoma Res 11: 205-212, 2001.

10. Ciolczyk-Wierzbicka D, Gil D, Hoja-Lukowicz D, Litynska A and Laidler P: Carbohydrate moieties of N-cadherin from human melanoma cell lines. Acta Biochim Pol 49: 991-999, 2002. 
11. Hsu CC, Lin TW, Chang WW, Wu CY, Lo WH, Wang PH and Tsai YC: Soyasaponin-I-modified invasive behavior of cancer by changing cell surface sialic acids. Gynecol Oncol 96: 415-422, 2005.

12. Chang WW, Yu CY, Lin TW, Wang PH and Tsai YC: Soyasaponin I decreases the expression of alpha 2,3-linked sialic acid on the cell surface and suppresses the metastatic potential of B16F10 melanoma cells. Biochem Biophys Res Commun 341: 614-619, 2006.

13. Burchell J, Mungul A and Taylor-Papadimitriou J: O-linked glycosylation in the mammary gland: changes that occur during malignancy. Mammary Gland Biol Neoplasia 6: 355-364, 2001.

14. Brockhausen I: Mucin-type O-glycans in human colon and breast cancer: glycodynamics and functions. EMBO Rep 7: 599-604, 2006

15. Yamashita K, Sakuramoto S, Kikuchi S, Katada N, Kobayashi N and Watanabe M: Validation of staging systems for gastric cancer. Gastric Cancer 11: 111-118, 2008

16. Czyzewska J, Guzińska-Ustymowicz K, Kemona A and Bandurski R: The expression of matrix metalloproteinase 9 and cathepsin B in gastric carcinoma is associated with lymph node metastasis, but not with postoperative survival. Folia Histochem Cytobiol 46: 57-64, 2008.

17. Wang FL, Cui SX, Sun LP, et al: High expression of $\alpha 2,3$-sialic acid residues is associated with the metastatic potential of human gastric cancer. Cancer Detect Prev 32: 437-443, 2009.

18. Ohyama C, Hosono M, Nitta K, et al: Carbohydrate structure and differential binding of prostate specific antigen to Maackia amurensis lectin between prostate cancer and benign prostate hypertrophy. Glycobiology 14: 671-679, 2004.

19. Raval GN, Patel DD, Parekh LJ, Patel JB, Shah MH and Patel PS: Evaluation of serum sialic acid, sialyltransferase and sialoprotein in oral cavity cancer. J Oral Dis 9: 119-128, 2003.

20. Dall'Olio F and Chiricolo M: Sialyltransferases in cancer Glycoconj J 18: 841-850, 2001.

21. Mahal LK, Charter NW, Angata K, Fukuda M, Koshland DE Jr and Bertozzi CR: A small-molecule modulator of poly-alpha 2,8-sialic acid expression on cultured neurons and tumor cells. Science 294: 380-381, 2001.

22. Seales EC, Jurado GA, Singhal A and Bellis SL: Ras oncogene directs expression of a differentially sialylated, functionally altered beta1 integrin. Oncogene 22: 7137-7145, 2003.

23. Fuster MM and Esko JD: The sweet and sour of cancer: glycan as novel therapeutic targets. Nat Rev Cancer 5: 526-542, 2005.
24. Kannagi R, Izawa M, Koike T, Miyazaki K and Kimura N: Carbohydrate-mediated cell adhesion in cancer metastasis and angiogenesis. Cancer Sci 95: 377-384, 2004.

25. Taniguchi A, Hioki $M$ and Matsmoto K: Transcriptional regulation of human ST4GalIV gene in testis and ovary cell line. Biochem Biophys Res Commun 301: 764-768, 2003.

26. Sotiropoulou G, Kono M, Anisowicz A, Stenman G, Tsuji S and Sager R: Identification and functional characterization of a human GalNAc2,6-sialyltransferase with altered expression in breast cancer. Mol Med 8: 42-55, 2002.

27. Imberty A, Gautier C, Lescar J, Pérez S, Wyns L and Loris R: An unusual carbohydrate binding site revealed by the residues of two Maackia amurensis lectins complexed with sialic acidcontaining oligosaccharides. J Biol Chem 275: 17541-17548, 2000.

28. Lee M, Lee HJ, Seo WD, Park KH and Lee YS: Sialylation of integrin betal is involved in radiation-induced adhesion and migration in human colon cancer cells. Int J Radiat Oncol Biol Phys 76: 1528-1536, 2010.

29. Chen S and Fukuda M: Cell type-specific roles of carbohydrates in tumor metastasis. Methods Enzymol 416: 371-380, 2006.

30. Miyazaki K, Ohmori K, Izawa M, et al: Loss of disialyl Lewis(a), the ligand for lymphocyte inhibitory receptor sialic acid-binding immunoglobulin-like lectin-7 (Siglec-7) associated with increased sialyl Lewis(a) expression on human colon cancers. Cancer Res 64: 4498-4505, 2004.

31. Hynes RO: Integrins: bidirectional, allosteric signaling machines. Cell 110: 673-687, 2002.

32. Damsky $\mathrm{CH}$ and Ilić D: Integrin signaling: it's where the action is. Curr Opin Cell Biol 14: 594-602, 2002.

33. Seales EC, Jurado GA, Brunson BA, Wakefield JK, Frost AR and Bellis SL: Hypersialylation of betal integrins, observed in colon adenocarcinoma, may contribute to cancer progression by up-regulating cell motility. Cancer Res 65: 4645-4652, 2005.

34. Christie DR, Shaikh FM, Lucas JA IV, Lucas JA III and Bellis SL: ST6Gal-I expression in ovarian cancer cell promotes an invasive phenotype by altering integrin glycosylation and function. J Ovarian Res 1: 3-10, 2008

35. Hedlund M, Ng E, Varki A and Varki NM: alpha 2-6-Linked sialic acids on $\mathrm{N}$-glycans modulate carcinoma differentiation in vivo. Cancer Res 68: 388-394, 2008. 